\title{
Trends of Components of the Metabolic Syndrome in German First Graders Throughout 10 Years: The PEP Family Heart Study
}

\author{
Gerda-Maria Haas, ${ }^{1}$ Thomas Bertsch, ${ }^{2}$ and Peter Schwandt ${ }^{1,3}$ \\ ${ }^{1}$ Arteriosklerose-Präventions-Institut, 81477 München, Germany \\ ${ }^{2}$ Institute of Clinical Chemistry, Klinikum Nürnberg, 90419 Nürnberg, Germany \\ ${ }^{3}$ Ludwig-Maximilians-Universität München, 80539 München, Germany
}

Correspondence should be addressed to Peter Schwandt, api.schwandt.haas@t-online.de

Received 24 April 2012; Accepted 16 May 2012

Academic Editor: Roya Kelishadi

Copyright (C) 2012 Gerda-Maria Haas et al. This is an open access article distributed under the Creative Commons Attribution License, which permits unrestricted use, distribution, and reproduction in any medium, provided the original work is properly cited.

\begin{abstract}
Although childhood overweight and obesity are increasing worldwide, some countries report trends for stabilization. However, the trend for the potentially atherogenic components of the metabolic syndrome (MetS) in children and adolescents is not well understood. Therefore, the purpose of this study was to analyze the trend of the five components of over 10 years in 2228 first graders aged 6 years. Waist circumference (WC) remained mainly unchanged between 1994 and 2003 whereas the other four components continuously decreased. In boys and girls mean values of triglycerides ( $-25.9 \%$ and $-28.6 \%$, resp.), HDL cholesterol ( $-19.8 \%$ and $-23.4 \%$, resp.), fasting glucose $(-7.3 \%$ and $-9 \%$, resp.), systolic $(-3.8 \%$ and $-4.1 \%$, resp. $)$, and diastolic $(-10.2 \%$ and $-9.7 \%$, resp.) blood pressure significantly decreased. Whereas the prevalence of abdominal adiposity was stable at baseline and after 10 years $(-1 \%$ in boys and $+2 \%$ in girls), the prevalence of hypertension, hypertriglyceridemia, low HDL-C, and glucose was very low without any trend.
\end{abstract}

\section{Introduction}

Overweight, obesity, and the metabolic syndrome (MetS) are an emerging health problem in industrialized and developing countries $[1,2]$. Ethnic disparities are reported regarding the prevalence of MetS, which was four times higher in Iranian than in German adolescents as well as regarding single components in terms of considerably higher prevalence of dyslipidemia in Brazilian and Iranian compared with German youths $[3,4]$.

Secular trends of childhood overweight and obesity in terms of increased body mass index (BMI) are heterogeneous in different countries with a large variation across countries [5-7]. However, BMI is not a component of the metabolic syndrome (MetS) according to the International Diabetes Federation (IDF) defining central obesity for children and adolescents as waist circumference (WC) at or above the 90th percentile [8]. Increasing prevalence of central adiposity indicates increasing cardiovascular risk $[9,10]$. Furthermore, early elementary school years are a critical period for increases in obesity prevalence sharply increasing from $10.4 \%$ to $19.6 \%$ below and above age six years [11]. Therefore, the purpose of this study was to assess the trend of the five single components over 10 years in a large sample of sixyear-old first graders.

\section{Material and Methods}

We investigated 2228 German first graders (1116 boys and 1112 girls, median age 6.0 years) who participated in yearly cross-sectional surveys between 1994 and 2003. Continuously trained research assistants measured waist circumference (WC), systolic and diastolic blood pressure (BP), fasting triglycerides (TG), high-density cholesterol (HDL-C), and fasting plasma glucose (FPG) as previously described [12]. We used the IDF cut-offs for the five MetS components in terms of $\mathrm{WC} \geq 90$ th percentile, $\mathrm{SBP} \geq 130$ or $\mathrm{DBP} \geq$ $85 \mathrm{~mm} \mathrm{Hg}, \mathrm{TG} \geq 1.7 \mathrm{mmol} / \mathrm{L}, \mathrm{HDL}-\mathrm{C} \leq 1.03 \mathrm{mmol} / \mathrm{L}$ and glucose $\geq 5.6 \mathrm{mmol} / \mathrm{L}[8]$. 


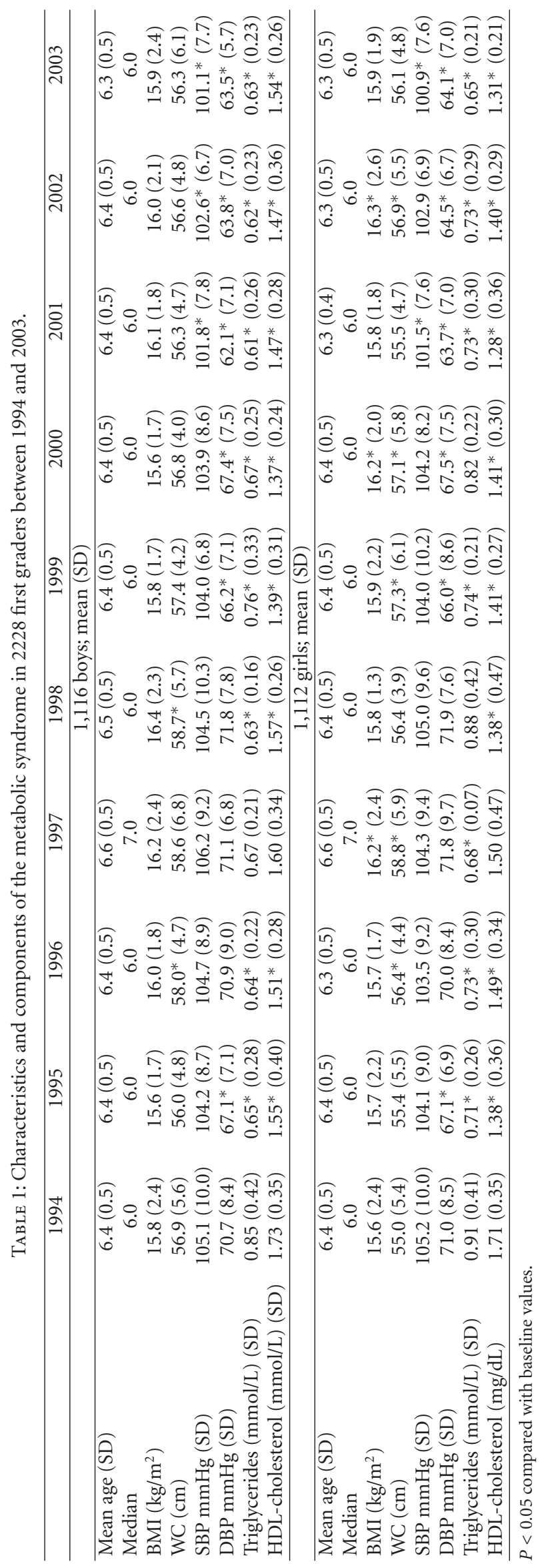


TABle 2: Prevalence (\%) of the five components of MetS according to the IDF definition in 2228 German first graders between 1994 and 2003.

\begin{tabular}{|c|c|c|c|c|}
\hline $\begin{array}{l}\text { Year of enrollment of } \\
\text { first graders }\end{array}$ & WC $\geq 90$ th percentile & $\mathrm{TG} \geq 1.7 \mathrm{mmol} / \mathrm{L}$ & $\mathrm{HDL}-\mathrm{C} \leq 1.03 \mathrm{mmol} / \mathrm{L}$ & $\begin{array}{l}\mathrm{SBP} \geq 130 \mathrm{mmHg} \\
\mathrm{DBP} \geq 85 \mathrm{mmHg}\end{array}$ \\
\hline \multicolumn{5}{|c|}{ boys } \\
\hline 1994 & 9.6 & 4.2 & 1.8 & 0 \\
\hline 1995 & 5.3 & 2.9 & 7.8 & 0 \\
\hline 1996 & 12.1 & 0 & 5.6 & 0 \\
\hline 1997 & 10.7 & 0 & 0 & 3.6 \\
\hline 1998 & 19.1 & 0 & 0 & 2.1 \\
\hline 1999 & 7.6 & 3.3 & 10.0 & 0 \\
\hline 2000 & 6.7 & 0 & 8.3 & 0 \\
\hline 2001 & 6.5 & 0 & 0 & 0 \\
\hline 2002 & 6.8 & 0 & 10.8 & 0 \\
\hline 2003 & 9.1 & 0 & 5.9 & 0 \\
\hline \multicolumn{5}{|c|}{ girls } \\
\hline 1994 & 6.7 & 4.8 & 0.7 & 0 \\
\hline 1995 & 5.5 & 0 & 14.0 & 0 \\
\hline 1996 & 8.3 & 0 & 5.2 & 1 \\
\hline 1997 & 18.8 & 0 & 20.0 & 6.3 \\
\hline 1998 & 6.5 & 8.3 & 8.3 & 0 \\
\hline 1999 & 12.7 & 0 & 4.8 & 0 \\
\hline 2000 & 10.8 & 0 & 9.4 & 0 \\
\hline 2001 & 9.5 & 0 & 26.3 & 1.6 \\
\hline 2002 & 11.3 & 0 & 7.7 & 0 \\
\hline 2003 & 11.4 & 0 & 18.9 & 0 \\
\hline
\end{tabular}

WC indicates waist circumference, TG: triglycerides, HDL-C: high-density lipoprotein cholesterol, SBP: systolic blood pressure, DBP: diastolic blood pressure.

For statistical analyses, we used SPSS 18.0 and the Kruskal-Wallis rank test for multisample ordinal comparisons, the Wilcoxon rank-sum test for pairwise comparisons and for linear trends across time ANOVA. $P<0.05$ was considered significant.

\section{Results and Discussion}

As presented in Table 1 mean values of waist circumference ( $-1 \%$ in boys and $+2 \%$ in girls) and of body mass index ( +0.6 in boys $+1.9 \%$ in girls) remained stable between 1994 and 2003. This is consistent with the stabilization of BMI between 1999 and 2010 among children and adolescents in USA, UK, and Sweden [13-15]. In Stockholm, the prevalence of obesity differed in 10 -year-old boys by $+0.6 \%$ and in girls by $-1.6 \%$ between 1999 and 2003 which is comparable with the urban area of Nuremberg [15]. "Mean WC greatly increased among US children between 1988-1994 and 19992004" [13]. However, among 2-5-year-old children the increase was $+2.3 \%$ in boys and $+1.6 \%$ in girls and among $6-11$-year-old children WC increased by $+4.2 \%$ in boys and $+4.9 \%$ in girls. We found a slight decrease by $-1 \%$ in boys respectively, a slight increase by $+2 \%$ in girls from 1994 to 2003 among 6-year-old first graders. These small differences between the monocentric PEP Family Heart Study using the same staff, location, and equipment and the NHANES design, which includes different ethnicities, are remarkable though different measuring points for WC were used (midway between lowest rib and iliac crest versus high point of the iliac crest). Furthermore, periods of assessment are different as well as age (6-year olds and ages 6-11 years). Among Australian children the mean WC $\mathrm{z}$-score in 2-16-year-old children increased more in girls than in boys at a faster rate than BMI between 1985 and 2007 [9]. In Spanish adolescents and in British adolescents and children aged 2-5 years WC increased significantly in both genders from 1995 to 20002002, respectively, from 1977 to 1997 [16-18]. A recent review compares mean values of WC in 6-year-old children from 11 countries [19].

However, the mean values of the other four components of MetS significantly decreased (Table 1). The strongest decrease was observed for mean TG $(-25.9 \%$ in boys, $-28.6 \%$ in girls $)$ and HDL-C $(-19.8 \%$ in boys, $-23.4 \%$ in girls). DBP $(-10.2 \%$ in boys, $-9.7 \%$ in girls $)$ and SBP $(-3.8 \%$ in boys, $-4.1 \%$ in girls) decreased less, and fasting glucose $(-7.3 \%$ in boys, $-9 \%$ in girls) was available only for the last 4 years. Because all measurements were performed at entry in the PEP Family Heart Study before any lifestyle advice was implemented, we suggest that the decrease of the nonanthropometric risk variables might be due to secular changes.

We registered no clear trend of the prevalence of four MetS components between 1994 and 2003 among 6-year-old children except for glucose for the last four years of the study, 
however unavailable values from the years before (Table 2). The prevalence of abdominal obesity decreased in boys ( $-0.5 \%$ from $9.6 \%$ at baseline) but increased in girls $(+4.7 \%$ from $6.7 \%$ at baseline). In children with abdominal obesity the interrelationship with hypertension $\left(\chi^{2}=29.3, P<\right.$ $0.001)$ and hypertriglyceridemia $\left(\chi^{2}=4.6, P=0.013\right)$ was significant, and the interrelationship between hypertriglyceridemia and low HDL-C was $\left(\chi^{2}=39.8, P<0.001\right)$. In 1994 the prevalence of raised triglycerides (4.2\% in boys and $4.8 \%$ in girls) and of low HDL-C (1.8\% in boys and $0.7 \%$ in girls) was far less than $21.5 \%$, respectively, $18.7 \%$ in $5-17.9$ year-old obese children in European Union in 2006 [14]. The highest prevalence of hypertension in 6-year-old was 3.6\% in boys and 6.3\% in girls in 1997 and was considerably lower than in European Union in 2006. A very large European multicenter study in 26008 overweight children reported that $50 \%$ had at least one cardiovascular risk factor related to the degree of overweight in terms of high BMI [20]. Since only $5.9 \%$ of the 12.6 -year-old children were normal weight, the risk factor profiles cannot be compared with mainly normalweight first graders of the current study, which however focused on WC as the major MetS component. Furthermore, studies from Germany reporting secular trends of BMI did not present nonanthropometric risk variables [21-24].

This is the first study documenting stable mean values of waist circumference and decreasing trends for the mean other four components of the metabolic syndrome over 10 years in first graders at the critical age of six years. However, it is unclear whether stable WC reflects a plateau between 1994 and 2003 and whether continuous decrease of MetS components mean values indicates leveling off in cardiovascular risk. Further strength of this monocentric study is constancy of staff, location, procedures, methods, and equipment and that all first graders lived in the same PEP families over ten years. A limitation of this study is the low prevalence of MetS components in this large cohort, which only allows a trend analysis of mean values regarding the four nonanthropometric variables. A further limitation is the relatively small sample size of 2228 first graders to detect a $10 \%$ difference between changes of prevalence [13]. Furthermore, the percentage of children with central obesity ( $\geq 90$ th percentile) was too small for categorizing the participants in prevalence groups of high WC ( $\geq 85 \mathrm{th}, \geq 95 \mathrm{th}$, $\geq 97$ th, and $\geq 99$ th percentiles) as has been done for Californian adolescents. This very large study (8.3 million multiethnic adolescents) was powered to demonstrate declining prevalence of high BMI for some groups but not for Indian and black girls [25].

\section{Conclusions}

This is the first study presenting ten years' trends of the mean values of the five components of the metabolic syndrome according to the definition of the International Diabetes Federation in first graders. Mean values of waist circumference as well as the prevalence of abdominal adiposity remained stable in 6-year-old children between 1994 and 2003. But the prevalence of hypertension, hypertriglyceridemia, low HDL-C, and hyperglycemia were low and inconsistent though mean values of blood pressure, triglycerides, HDLcholesterol, and glucose decreased continuously in both genders.

Longitudinal studies are needed to confirm these disparate trends.

\section{Conflict of Interests}

None of the authors has a conflict of interest.

\section{Acknowledgments}

The authors thank the families participating in this project for their outstanding cooperation and dedication. For their excellent work and engagement, they thank the study staff and the many physicians and nurses for blood collection. All authors read and approved the final paper. This paper is funded by Foundation for the Prevention of Atherosclerosis, Nuremberg, Germany; Ludwig Maximilian University, Munich, Germany; Bavarian Ministry of Health, Munich; City of Nuremberg.

\section{References}

[1] C. L. Ogden, S. Z. Yanovski, M. D. Carroll, and K. M. Flegal, "The epidemiology of obesity," Gastroenterology, vol. 132, no. 6, pp. 2087-2102, 2007.

[2] R. Kelishadi, "Childhood overweight, obesity, and the metabolic syndrome in developing countries," Epidemiologic Reviews, vol. 29, no. 1, pp. 62-76, 2007.

[3] P. Schwandt, R. Kelishadi, and G. M. Haas, "Ethnic disparities of the metabolic syndrome in population-based samples of German and Iranian adolescents," Metabolic Syndrome and Related Disorders, vol. 8, no. 2, pp. 189-192, 2010.

[4] P. Schwandt, R. Kelishadi, R. Q. C. Ribeiro, G. M. Haas, and P. Poursafa, "A three-country study on the components of the metabolic syndrome in youths: the BIG Study," International Journal of Pediatric Obesity, vol. 5, no. 4, pp. 334-341, 2010.

[5] Y. Wang and T. Lobstein, "Worldwide trends in childhood overweight and obesity," International Journal of Pediatric Obesity, vol. 1, no. 1, pp. 11-25, 2006.

[6] B. Rokholm, J. L. Baker, and T. I. A. Sørensen, "The levelling off of the obesity epidemic since the year 1999-a review of evidence and perspectives," Obesity Reviews, vol. 11, no. 12, pp. 835-846, 2010.

[7] J. C. Han, D. A. Lawlor, and S. Y. Kimm, "Childhood obesity," The Lancet, vol. 375, no. 9727, pp. 1737-1748, 2010.

[8] P. Zimmet, G. Alberti, F. Kaufman et al., "The metabolic syndrome in children and adolescents," The Lancet, vol. 369, no. 9579, pp. 2059-2061, 2007.

[9] S. P. Garnett, L. A. Baur, and C. T. Cowell, "The prevalence of increased central adiposity in Australian school children 1985 to 2007," Obesity Reviews, vol. 12, pp. 887-896, 2011.

[10] H. S. Kahn, G. Imperatore, and Y. J. Cheng, "A populationbased comparison of BMI percentiles and waist-to-height ratio for identifying cardiovascular risk in youth," Journal of Pediatrics, vol. 146, no. 4, pp. 482-488, 2005.

[11] A. Datar, V. Shier, and R. Sturm, "Changes in body mass during elementary and middle school in a national cohort of Kindergarteners," Pediatrics, vol. 128, pp. e1411-e1417, 2011.

[12] P. Schwandt, H. C. Geiß, M. M. Ritter et al., "The Prevention Education Program (PEP). A prospective study of the efficacy 
of family-oriented life style modification in the reduction of cardiovascular risk and disease: design and baseline data," Journal of Clinical Epidemiology, vol. 52, no. 8, pp. 791-800, 1999.

[13] C. L. Ogden, M. D. Carroll, B. K. Kit, and K. M. Flegal, "Prevalence of obesity and trends in body mass index among US children and adolescents 1999-2010," Japan Automobile Manufacturers Association, vol. 307, pp. 483-490, 2012.

[14] R. R. Kipping, R. Jago, and D. A. Lawlor, "Obesity in children. Part 1: epidemiology, measurement, risk factors, and screening," British Medical Journal, vol. 337, no. 7675, pp. 922-927, 2008.

[15] E. Sundblom, M. Petzold, F. Rasmussen, E. Callmer, and L. Lissner, "Childhood overweight and obesity prevalences levelling off in Stockholm but socioeconomic differences persist," International Journal of Obesity, vol. 32, no. 10, pp. 1525-1530, 2008.

[16] L. A. Moreno, A. Sarría, J. Fleta, A. Marcos, and M. Bueno, "Secular trends in waist circumference in Spanish adolescents, 1995 to 2000-02," Archives of Disease in Childhood, vol. 90, no. 8, pp. 818-819, 2005.

[17] H. D. McCarthy, S. M. Ellis, and T. J. Cole, "Central overweight and obesity in British youth aged 11-16 years: cross sectional surveys of waist circumference," British Medical Journal, vol. 326, no. 7390, pp. 624-626, 2003.

[18] H. D. McCarthy, K. V. Jarrett, P. M. Emmett, and I. Rogers, "Trends in waist circumferences in young British children: a comparative study," International Journal of Obesity, vol. 29, no. 2, pp. 157-162, 2005.

[19] P. Schwandt and G. M. Haas, "Waist circumference in children and adolescents from different ethnicities," in Childhood Obesity, Sevil Ari Yuca, Ed., chapter 4, 2012, http://www.in-techopen.com/.

[20] D. I'Allemand, S. Wiegand, T. Reinehr et al., "Cardiovascular risk in 26,008 European overweight children as established by a multicenter database," Obesity, vol. 16, no. 7, pp. 1672-1679, 2008.

[21] C. Meigen, A. Keller, R. Gausche et al., "Secular trends in body mass index in German children and adolescents: a crosssectional data analysis via CrescNet between 1999 and 2006," Metabolism, vol. 57, no. 7, pp. 934-939, 2008.

[22] H. Kalies, J. Lenz, and R. von Kries, "Prevalence of overweight and obesity and trends in body mass index in German preschool children, 1982-1997," International Journal of Obesity, vol. 26, no. 9, pp. 1211-1217, 2002.

[23] K. Kromeyer-Hauschild and K. Zellner, "Trends in overweight and obesity and changes in the distribution of body mass index in schoolchildren of Jena, East Germany," European Journal of Clinical Nutrition, vol. 61, no. 3, pp. 404-411, 2007.

[24] A. Moss, J. Klenk, K. Simon, H. Thaiss, T. Reinehr, and M. Wabitsch, "Declining prevalence rates for overweight and obesity in German children starting school," European Journal of Pediatrics, vol. 171, pp. 289-299, 2011.

[25] K. A. Madsen, A. E. Weedn, and P. B. Crawford, "Disparities in peaks, plateaus, and declines in prevalence of high BMI among adolescents," Pediatrics, vol. 126, no. 3, pp. 434-442, 2010. 


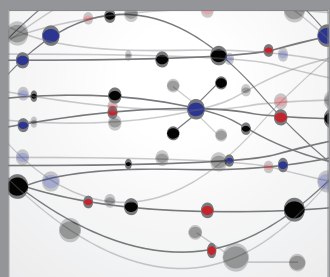

The Scientific World Journal
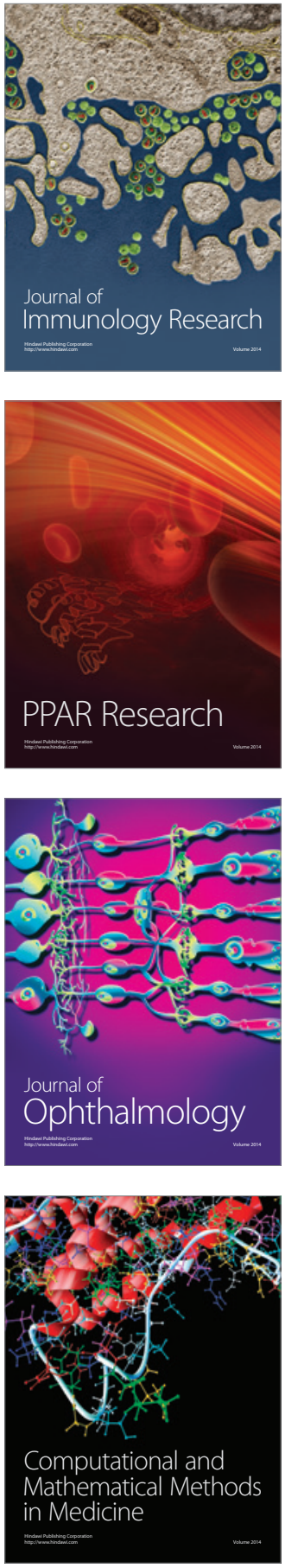

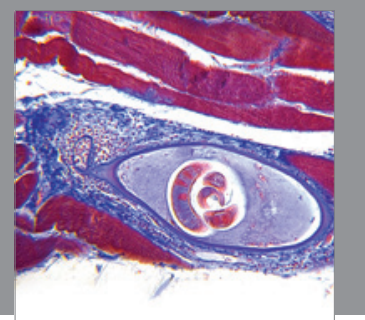

Gastroenterology

Research and Practice
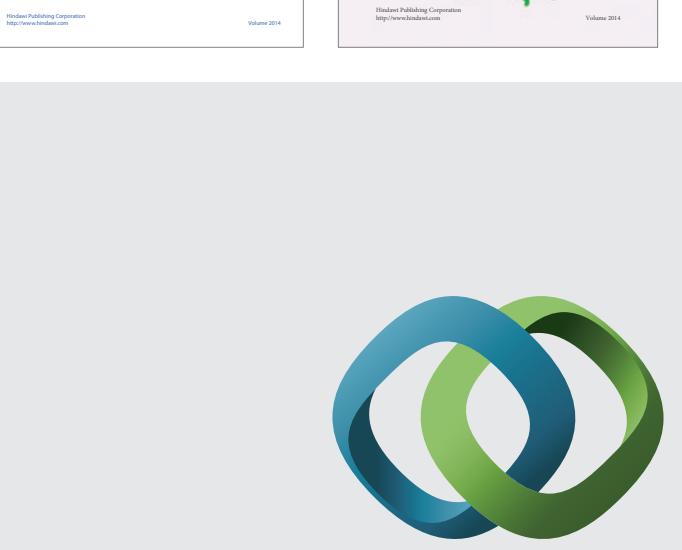

\section{Hindawi}

Submit your manuscripts at

http://www.hindawi.com
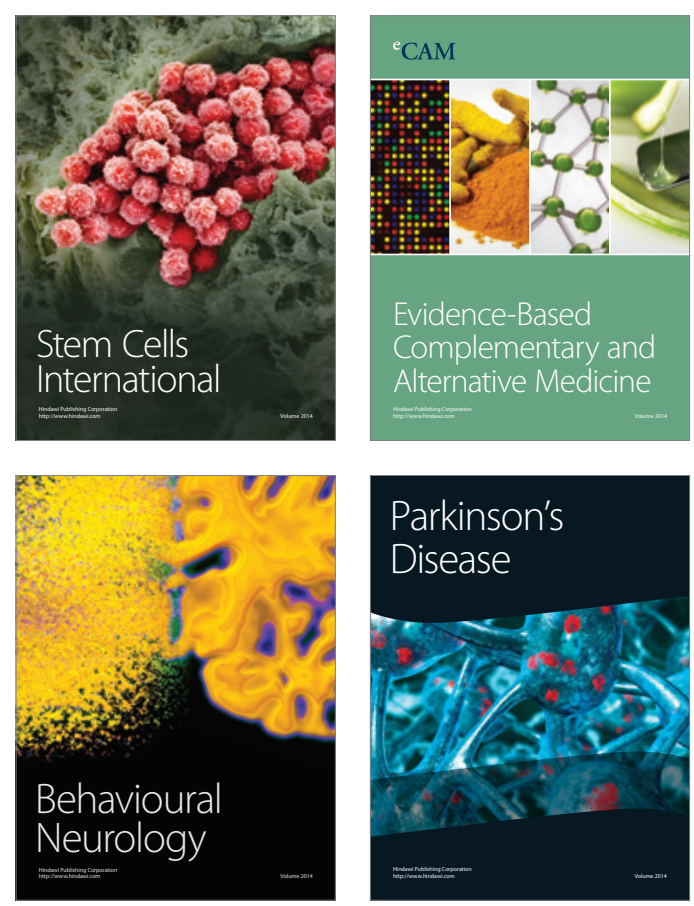

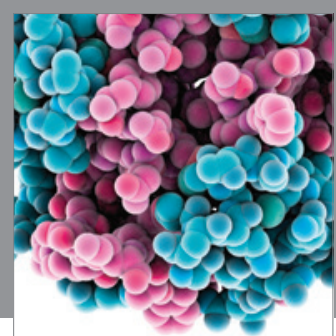

Journal of
Diabetes Research

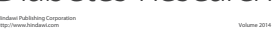

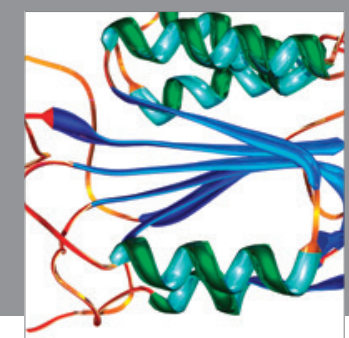

Disease Markers
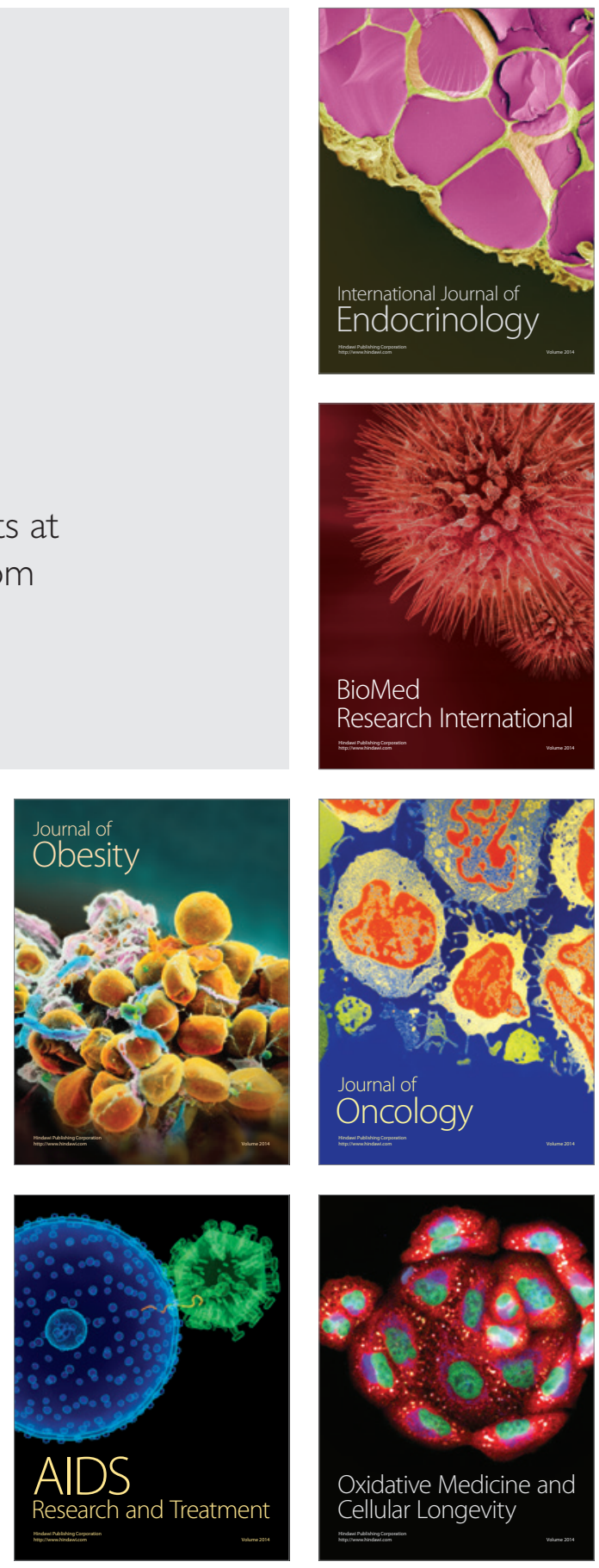